\title{
Corrigendum to "The Overexpression of NALP3 Inflammasome in Knee Osteoarthritis Is Associated with Synovial Membrane Prolidase and NADPH Oxidase 2"
}

\author{
Denise Clavijo-Cornejo, ${ }^{1}$ Karina Martínez-Flores, ${ }^{1}$ Karina Silva-Luna, ${ }^{2}$ \\ Gabriela Angélica Martínez-Nava, ${ }^{1}$ Javier Fernández-Torres, ${ }^{1,3}$ Yessica Zamudio-Cuevas, ${ }^{1}$ \\ Mónica Guadalupe Santamaría-Olmedo, ${ }^{1}$ Julio Granados-Montiel, ${ }^{4}$ \\ Carlos Pineda, ${ }^{5}$ and Alberto López-Reyes ${ }^{1}$ \\ ${ }^{1}$ Synovioanalysis Molecular Laboratory, Instituto Nacional de Rehabilitación "Luis Guillermo Ibarra Ibarra", \\ Secretaria de Salud, Calzada Mexico-Xochimilco No. 289, Col. Arenal de Guadalupe, 14389 Tlalpan, Mexico City, Mexico \\ ${ }^{2}$ Musculoskeletal and Articular Ultrasound Diploma Course, Instituto Nacional de Rehabilitación "Luis Guillermo Ibarra Ibarra", \\ Secretaria de Salud, Calzada Mexico-Xochimilco No. 289, Col. Arenal de Guadalupe, 14389 Tlalpan, Mexico City, Mexico \\ ${ }^{3}$ Biological and Health Sciences PhD Program, Universidad Autónoma Metropolitana Iztapalapa, Avenida San Rafael Atlixco 186, \\ Col. Vicentina, 09340 Iztapalapa, Mexico City, Mexico \\ ${ }^{4}$ Tissue Engineering, Cell Therapy and Regenerative Medicine Research Unit, \\ Instituto Nacional de Rehabilitación "Luis Guillermo Ibarra Ibarra", Secretaria de Salud, Calzada Mexico-Xochimilco No. 289, \\ Col. Arenal de Guadalupe, 14389 Tlalpan, Mexico City, Mexico \\ ${ }^{5}$ Instituto Nacional de Rehabilitación "Luis Guillermo Ibarra Ibarra", Secretaria de Salud, Calzada Mexico-Xochimilco 289, \\ Col. Arenal de Guadalupe, 14389 Tlalpan, Mexico City, Mexico
}

Correspondence should be addressed to Alberto López-Reyes; allorey@yahoo.com

Received 20 November 2016; Accepted 28 November 2016; Published 16 March 2017

Copyright (C) 2017 Denise Clavijo-Cornejo et al. This is an open access article distributed under the Creative Commons Attribution License, which permits unrestricted use, distribution, and reproduction in any medium, provided the original work is properly cited.

In the article titled "The Overexpression of NALP3 Inflammasome in Knee Osteoarthritis Is Associated with Synovial Membrane Prolidase and NADPH Oxidase 2," [1] an incorrect version of Figure 2(b) is published. The correct version is shown as follows. 


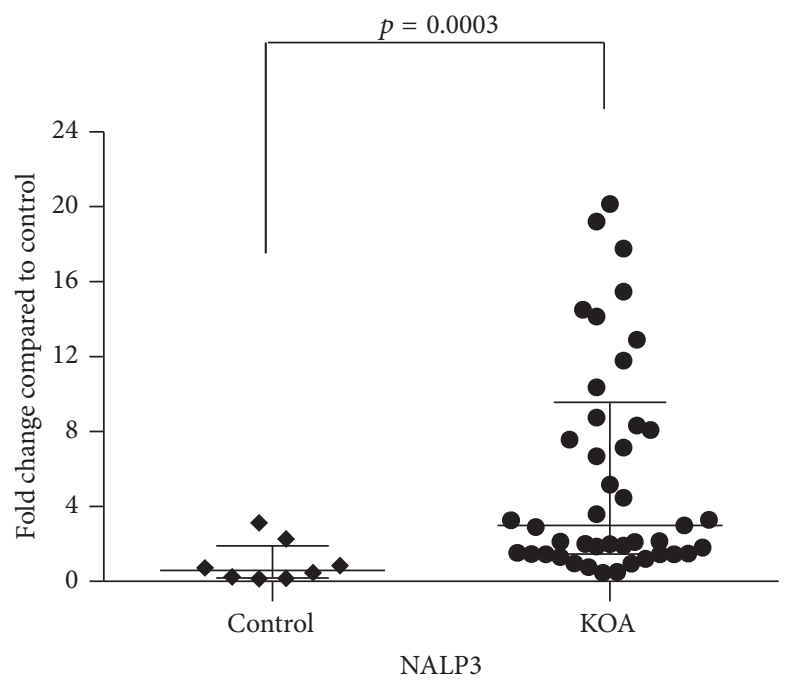

(a)

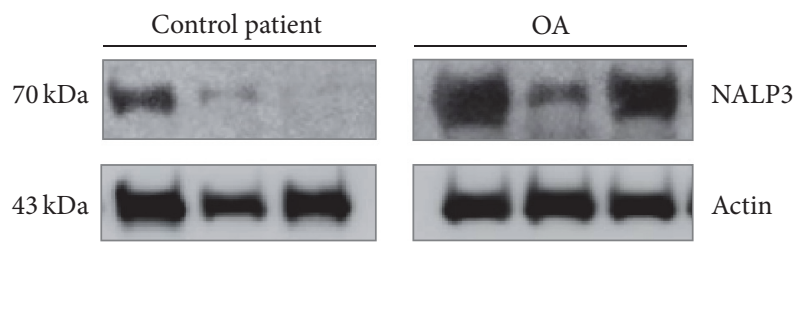

(b)

FIGURE 2: Inflammatory state present in KOA patients. Densitometry analysis of protein expression of NALP3 in comparison to the control group (a). Results are shown as the mean \pm SEM $(p<0.001)$. Representative Western blot of protein levels relative to actin used as internal control (b).

\section{References}

[1] D. Clavijo-Cornejo, K. Martínez-Flores, K. Silva-Luna et al., "The overexpression of NALP3 inflammasome in knee osteoarthritis is associated with synovial membrane prolidase and NADPH oxidase 2," Oxidative Medicine and Cellular Longevity, vol. 2016, Article ID 1472567, 7 pages, 2016. 


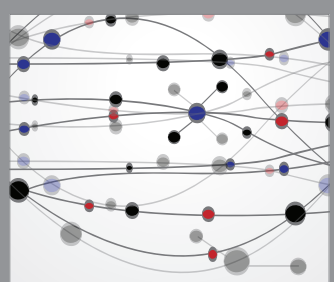

The Scientific World Journal
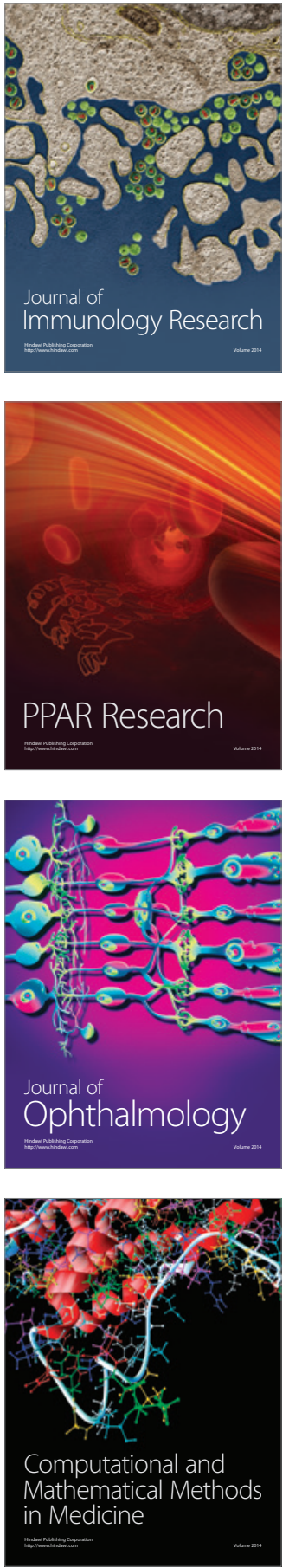

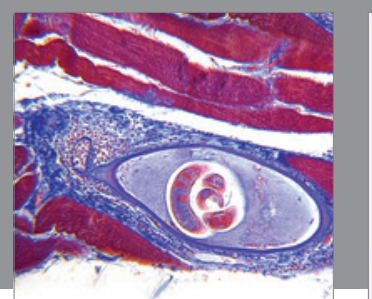

Gastroenterology Research and Practice
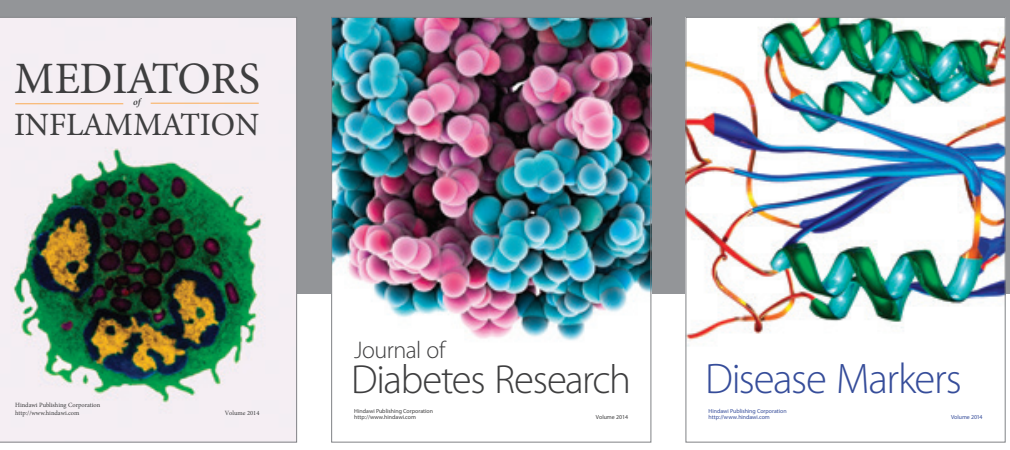

Disease Markers

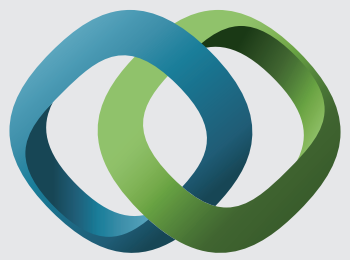

\section{Hindawi}

Submit your manuscripts at

https://www.hindawi.com
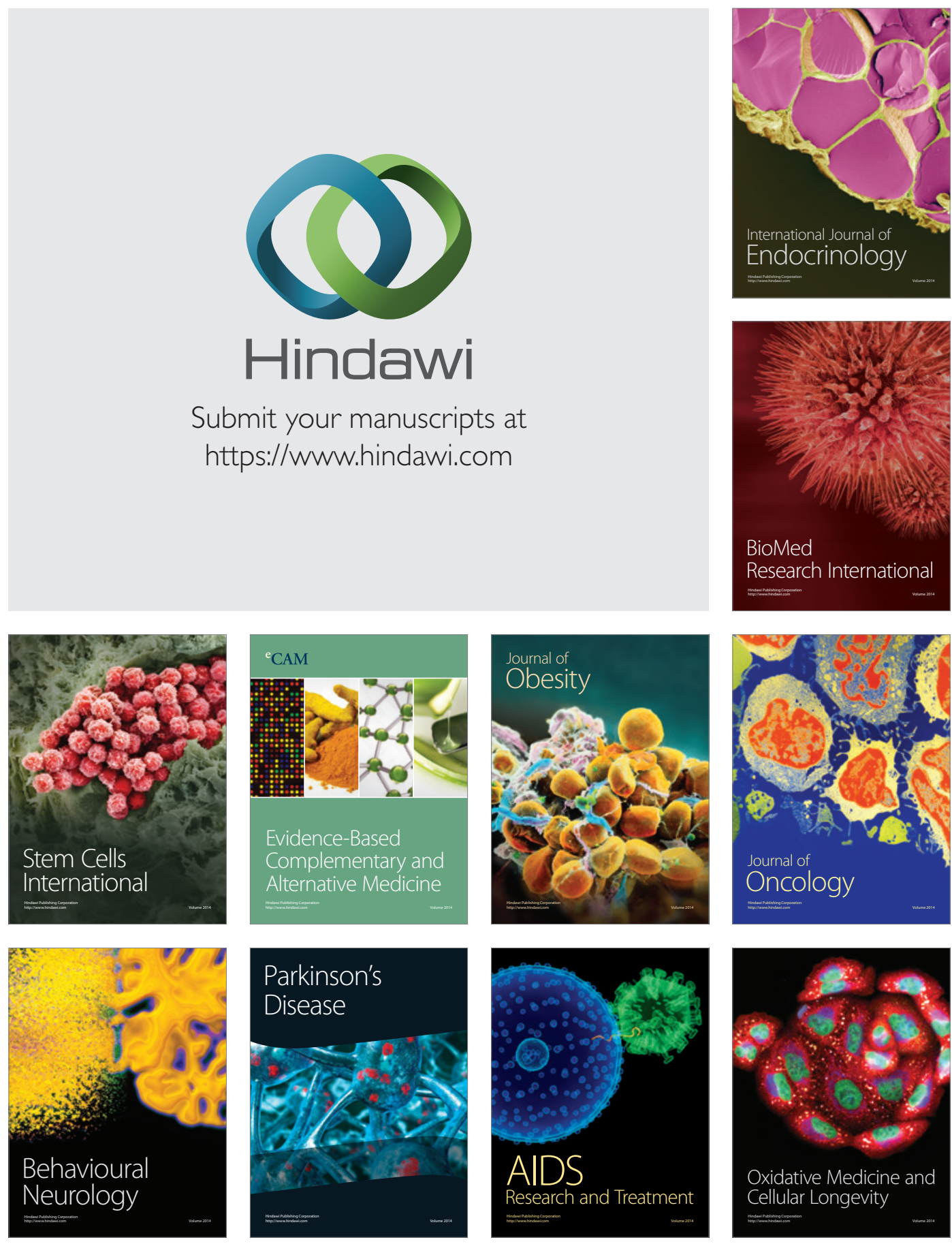